\title{
Factors increasing safety of the disabled road users
}

\author{
Monika Ucińska ${ }^{1, *}$, and Ewa Odachowska ${ }^{1}$ \\ ${ }^{1}$ Motor Transport Institute, Transport Telematics Center, 80 Jagiellońska Str., 03-301 Warsaw, Poland
}

\begin{abstract}
A report by the World Health Organization indicates that over one billion people in the world are affected by some form of disability or have limited fitness, and 200 million have difficulties in functioning [1]. In Poland, according to the statistics, there are 7.5 million people with functional limitations, including almost 2.5 million those in a significant degree [2]. Many people with different dysfunctions drive vehicles, among this group there are also older people, who, with age experience the reduction of many functions affecting the safe driving of the vehicle. To assess some factors increasing the safety of disabled participants in the road traffic, selected psychomotor aspects have been verified. This article presents analyses related to determining the capabilities of people with disabilities depending on whether the disability was congenital or acquired. These drivers were also compared with non-disabled road users. Psychomotor performance was checked using the DTS (Driver Test Station) device. It was noticed that people with acquired disability do better in the majority of tests measuring both pressure forces and reactions of particular limbs in comparison with people with a congenital disability. The research presented sets the direction for further explorations, mainly due to the small group of respondents, but they can nevertheless form the basis for further hypotheses and their verification.
\end{abstract}

\section{Introduction}

The need for unassisted mobility, ensuring independence and the opportunity to participate in social life, is one of the most important needs for people with disabilities, as well as older people, giving the prospect of autonomy. What distinguishes people with disabilities from others is damage to the body, which, due to its usually permanent nature, hinders normal functioning and carrying out tasks.

Disabled participants of the road traffic can do this thanks to the possibilities currently offered by the automotive market, in the form of adaptation to the most complex forms of disability.

Among the disorders occurring in the group of disabled people in Poland (according to with the statistics quoted earlier), the main place take people with dysfunctions of the mobility organs. Reduced mobility is one of the 12 types of disability, in which there are various types of deficiencies [3], including: the lack of limbs or parts of them, damage to

\footnotetext{
* Corresponding author: monika.ucinska@its.waw.pl
} 
the nervous system or muscular system in the part responsible for the functioning of the limbs, incorrect formation of the skeleton during the fetal development or growing period, joint damage. The dysfunctions indicated are either of congenital (or occurring from early childhood) or acquired character. Both the psychological effects that a person incurs and the way of dealing with disability depend on the period of life in which the dysfunction occurred and the degree of damage to the body All these elements will also affect possible functioning in social roles and activities, including the role of a driver.

Safety of the driver on the road depends on many factors, among which an important role is played by, among the others, appropriate health, psychophysical and perceptual fitness, emotional and social maturity. The factor that increases road safety is also a vehicle adapted to the type of disability.

\section{Time of the occurrence of disability as a factor affecting safety of the driver}

Safety of the driver on the road depends on many factors, among which an important role is played by, among the others, appropriate health, psychomotor and perceptual fitness, emotional and social maturity. In the case of people with disabilities, the degree and type of disability are also of importance. In the context of dealing with disability, including active participation in road traffic, the time of acquiring disability is also important, as indicated earlier.

The specificity of the psycho-physiological condition of a disabled person from birth differs significantly from that of a person who suffered an injury later in life. Such a person is deprived of all those reactions whose sources lie in the previous good state of their own health. This is due to a lack in the brain centres of representation of proper movements and a different way of functioning. A person is born with a disability or disability acquired in an early childhood, so there is no point of reference for his condition. The psychological problems that they experience may result from the effect of comparing themselves to healthy people, although this depends to a large extent on the degree of disability. Considering persons with injuries of the mobility organs of a congenital or very early acquired nature, they seem to bear lower costs physically and mentally resulting from disability than persons who acquired a disability later in life [4]. Such people need psychological support related to maintaining or building motivation for rehabilitation, work and social activity. The activation of such a person plays a key role here in order to achieve a much better quality of life.

The acquired disability relates to the situation in which the person develops properly and only becomes disabled due to an event. It may relate to a damage to mobility organs causing physical disability, sensory organs (sight, hearing and other) or damage to motor functions. Both the person who suffers the damage and her family faces a completely new, even extreme situation. Usually, the whole of family and social functioning must be reorganized due to the fact that the normal course of everyday affairs is disturbed. The implementation of psychic needs becomes the priority here. The reduction of social activity or even its complete cessation is another consequence of the disease [5]. Patients become more lonely due to the fact that healthy friends devote themselves to work and other activities, while those with disabilities remain at home. Being isolated from friends, resignation from work causes very severe emotional stress in people with disabilities that may worsen their health. In many cases, some people stop working due to their neurological status, significant fatigability, lack of material motivation, financial support received from their spouse or family, transport difficulties, etc. [5]. Some, however, seek to retrain and change their profession, continue their professional activity. This is possible, for example, by acquiring new skills, e.g. driving licenses. 
From the psychological point of view, the most difficult to accept is disability resulting from a traumatic event (e.g. a traffic accident) because in the case of a chronic disease, the person still has to improve their health and the disability usually occurs gradually, but in this case disability is the result of a violent event, often associated with a threat to life. The psychological consequences of these kinds of events are wide. A big problem is also the fact that people with disabilities often experience symptoms of post-traumatic stress as a result of a traumatic event, along with a general increase in the level of anxiety and emotional degradation that can lead to depression. Analyses found in the literature related to having a disability (congenital, acquired) focus on psychological consequences and dealing with disability mainly in the context of vocational activation.

\section{Own research}

To evaluate some factors increasing the safety of disabled participants in the road traffic, selected psychomotor aspects have been verified. The aim of the research was to determine the capabilities of people with disabilities depending on whether the disability was congenital or acquired. These drivers were also compared with non-disabled road users. This kind of research is also important in the context of emerging disabilities associated with aging processes, which can be regarded as acquired.

The study was conducted at the Motor Transport Institute in cooperation with PIMOT (Automotive Industry Institute). The study involved 46 people with disabilities (32 people with a significant degree and 12 with a moderate degree) and 15 people without disabilities. 21 people had acquired disability and 25 had congenital disability. Among the disabilities were as follows: cerebral palsy, spinal bifida, spinal muscular atrophy, polio, dwarfism, club foot, lack of a limb or limb paresis, juvenile idiopathic arthritis, arthrogryposis multiplex congenital. A purposeful selection was used, depending on the type of disability (congenital or acquired). Psychomotor performance was checked using the DTS (Driver Test Station) device, which is a tool to assess the ability of a person to drive a vehicle as far as, e.g. reaction times of individual limbs, pressure forces, motor coordination, capability to manoeuvre the steering wheel are concerned. The device has the opportunity to choose the right control knob tailored to your preferences and type of disability. This device enables to test the upper and lower limbs separately. Also, thanks to various tests, is allows to provide the selection of adaptations tailored to the individual capabilities of the person. The following tests were used in the study:

1. Power test, where the pressure on accelerator/brake and steering wheel turning is checked (DTS has a steering wheel inertia adjustment function).

2. Timer test (reaction time and movement coordination test) in which being checked is how well the driver manages to coordinate movements and how flexible the driver is in the situation of switching from one pedal to the other or from the accelerator lever to the brake.

3. Reaction test - Test of complex reaction time for all limbs depending on the stimulus.

4. Emergency brake test - reaction to green light on the traffic signal.

\section{Results}

The results analysis was performed by a one-way analysis of variances in the intergroup scheme using the Post-Hoc Bonfferronci test. In a few cases, there were statistically significant differences identified. The first statistically significant difference was noted in the range of the pressure force (Power test) on the accelerator in both the left $(\mathrm{F}(2.54)=$ $4.536, \mathrm{p}<0.05)$ and the right hand $(\mathrm{F}(2.51)=3.622 ; \mathrm{p}<0,05)$. Persons with congenital 
disability $(\mathrm{N}=25)$ achieved lower results (left hand $\mathrm{M}=10.99$, right hand $\mathrm{M}=11.10)$ in comparison to persons with acquired disability $(\mathrm{N}=21$ ) (left hand $\mathrm{M}=14.59$, right hand $M=13.35$ ), which means that these people were unable to exert with both the left hand and the right hand as much force as the other two groups tested when manoeuvring the accelerator lever located under the steering wheel on the left and the lever located on the right.

A

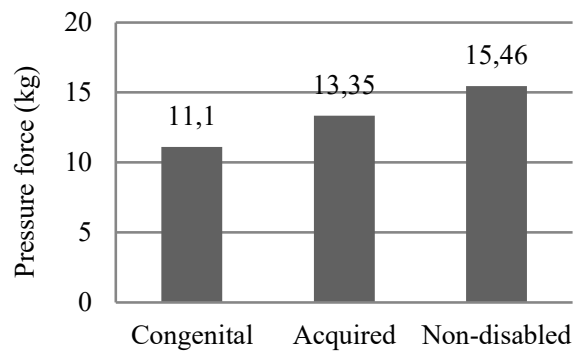

B

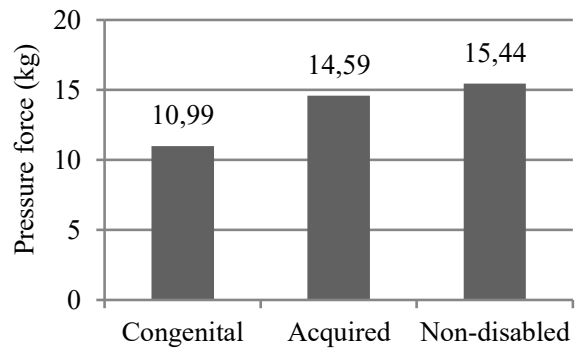

Fig. 1. Differences in the pressure force on the accelerator using upper limbs depending on the physical fitness ( $\mathrm{A}$ - right hand / $\mathrm{B}$ - left hand) $(\mathrm{N}=46)$.

Another statistically significant difference was noted in the steering force test in the case of turning the steering wheel (Power test) to the left $\mathrm{F}(2.55)=6.144 ; \mathrm{p}<0.05$. Persons with congenital disability $(\mathrm{N}=25)$ did worse $(\mathrm{M}=11.46)$ compared to people with acquired disabilities $(\mathrm{N}=21)(\mathrm{M}=12.01)$ and non-disabled persons $(\mathrm{N}=15)(\mathrm{M}=16.75)$. Which means that people with inborn disability had less strength (compared to two other groups) to turn the steering wheel to the left with steadily increasing resistance to the steering wheel. A similar relationship was observed when turning the steering wheel to the right $(\mathrm{F}$ $(2.55)=5.629, \mathrm{p}<0.05)$. People with congenital disability did worse $(\mathrm{M}=11.10)$ compared to people with acquired disability $(\mathrm{M}=11.53)$. Non-disabled people $(\mathrm{N}=15)$ achieved the best result $(\mathrm{M}=16.10)$. Which means that people with congenital disabilities had less strength (compared to two other groups) to turn the steering wheel to the right with steadily increasing resistance to the steering wheel.

A

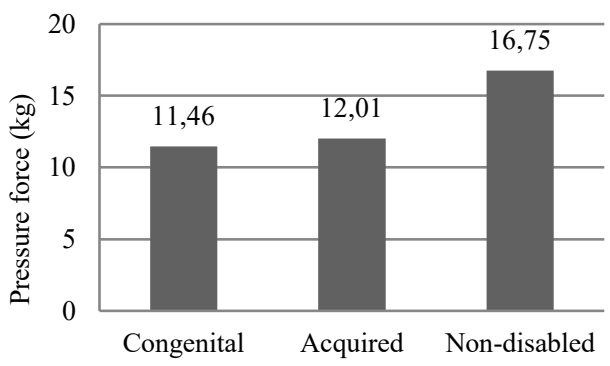

B

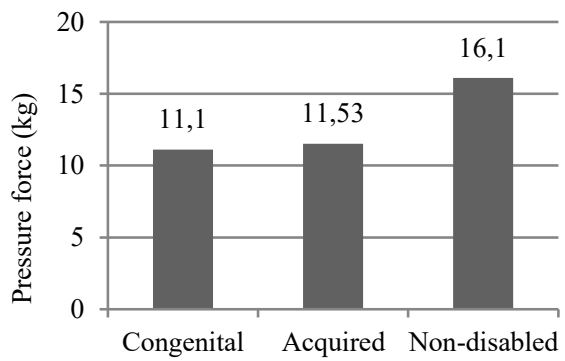

Fig. 2. Differences in the pressure force applied to the steering wheel using upper limbs depending on the physical fitness ( $\mathrm{A}$ - left side / $\mathrm{B}$ - right side) ( $\mathrm{N}=46)$.

A statistically significant difference was also found in the reaction time (Timer test) (lower limbs) F $(2.27)=3.60 ; \mathrm{p}<0.05$. This time, people with inborn disability $(\mathrm{N}=25)$ got 
better times $(\mathrm{M}=1.52)$ in comparison with people with acquired disability $(\mathrm{N}=21)$ $(\mathrm{M}=3.82)$ (non-disabled people achieved the best result $\mathrm{M}=0.63)$.

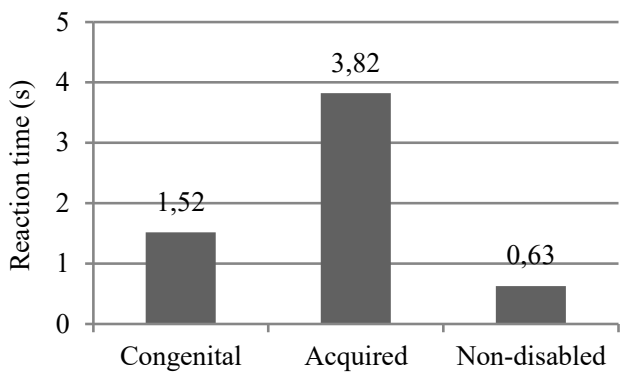

Fig. 3. Differences in reaction time - lower limbs $(\mathrm{N}=46)$.

In the case of the studying the reaction time in the distinction between upper limbs (left/right), a statistical tendency was demonstrated in the context of reaction time with the left upper limb F $(2.54)=3.017 ; \mathrm{p}=0.057$. People with congenital disability $(\mathrm{N}=25)$ had similar times $(\mathrm{M}=1.29)$ as people with acquired disability $(\mathrm{N}=21)(\mathrm{M}=1.30)$. These persons achieved twice as long reaction times as non-disabled people $(\mathrm{N}=15)(\mathrm{M}=0.63)$ in a situation when they had to react with their left hand for certain stimuli. There was a statistically significant difference shown in the reaction time with the right upper limb $\mathrm{F}(2.51)=4.030 ; \mathrm{p}<0.05$. People with congenital disability achieved worse results (they achieved longer times in response to a stimulus when they had to react with the right limb $\mathrm{M}=1.26)$ when compared with people with acquired disability $(\mathrm{M}=1.06)$ and nondisabled persons $(\mathrm{M}=0.56)$.

A

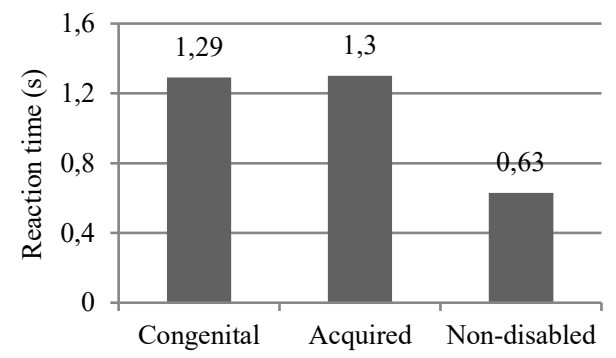

B

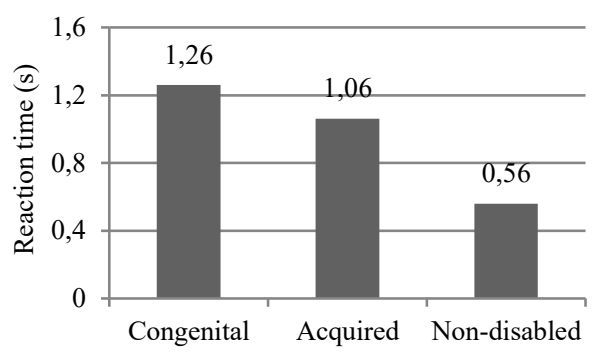

Fig. 4. Differences in the reaction time to stimuli depending on the upper limb (A - left hand / B right hand) $(\mathrm{N}=46)$.

There was a statistically significant difference shown in the complex reaction time (Reaction test), when the reaction concerned the acceleration pedal $\mathrm{F}(2.33)=10.513$; $\mathrm{p}<0.05$. Persons with congenital disability $(\mathrm{N}=25)$ achieved better results $(\mathrm{M}=3.27)$ than persons with the acquired disability $(\mathrm{N}=21)(\mathrm{M}=3.50)$. A reverse relationship was observed when the reaction concerned the brake pedal $\mathrm{F}(2.33)=5.887 ; \mathrm{p}<0.05$. Persons with congenital disability achieved worse results $(\mathrm{M}=3.10)$ than respondents with acquired disability $(\mathrm{M}=2.33)$ and non-disabled persons $(\mathrm{N}=15)(\mathrm{M}=1.03)$. This difference concerns the results of non-disabled people with regard to those with congenital disability. 


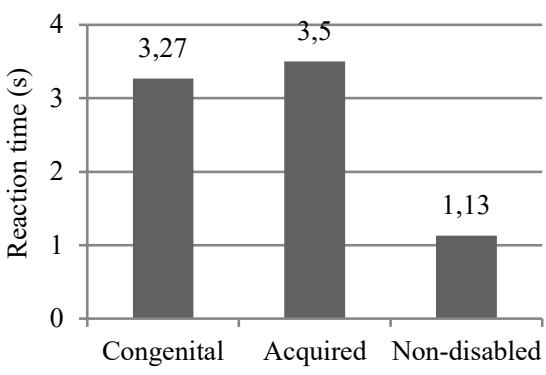

Fig. 5. Differences in the complex reaction time - acceleration pedal $(\mathrm{N}=46)$

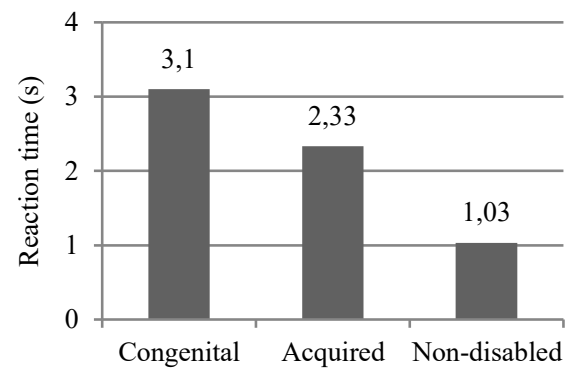

Fig. 6. Differences in the complex reaction time - brake pedal $(\mathrm{N}=46)$

A statistically significant difference was also found in the average complex reaction time $\mathrm{F}(2.42)=10.469 ; \mathrm{p}<0.05$. Persons with congenital disability $(\mathrm{N}=25)$ had worse results $(\mathrm{M}=12.70)$ compared to people with acquired disability $(\mathrm{N}=21)(\mathrm{M}=11.91)$ and non-disabled $(\mathrm{N}=15)(\mathrm{M}=6.40)$. This difference is significant because the response time for people with disabilities is extended by half.

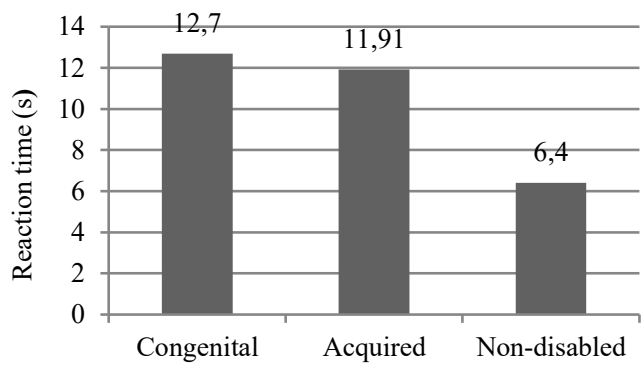

Fig. 7. Differences in the average complex reaction time $(\mathrm{N}=46)$

A statistically significant difference in reaction time was demonstrated in sudden emergency braking (Emergency brake test ) (leg-pedal) $(2.29)=9.974 ; p<0.05$. Persons with congenital disability $(\mathrm{N}=25)$ received a similar average as people with acquired disability $(\mathrm{N}=21)(\mathrm{M}=0.69)$ and non-disabled people $(\mathrm{N}=15)(\mathrm{M}=0.48)$. The difference concerned the results of non-disabled people in relation to both groups analysed.

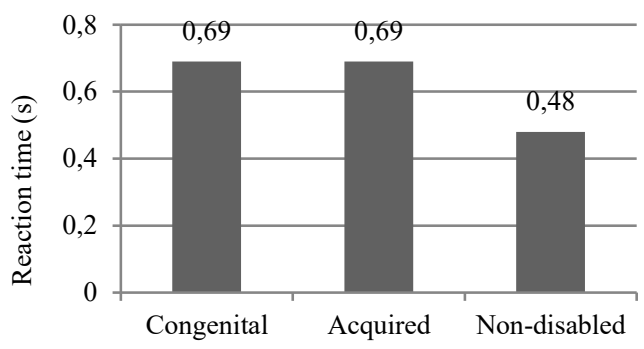

Fig. 8. Differences in the average reaction time - Emergency brake test (pedals) $(\mathrm{N}=46)$

There were no differences observed in the response time test (Emergency brake test ) with the upper limbs. 


\section{Conclusions}

There are many disabled people who actively participate in road traffic, while using either the upper limbs or lower limbs. Some of them after losing their physical fitness had to adjust to the acquired disability. The research was aimed at the verification of whether adjusting the vehicle to the appropriate dysfunctions will have an impact on safety. The most important aspect that was noticed in the analysis of research results refers to significant differences in many aspects between people with disabilities from birth and those who have lost the ability to move efficiently some time in life (as a result of an accident or illness). It was noticed that people with disability acquired do better in the majority of tests measuring both pressure forces and reactions of particular limbs in comparison with people with a disability inborn. Obviously, these efficiencies differ significantly from those obtained by non-disabled drivers, but statistically significant differences were observed between persons with congenital and acquired dysfunctions.

The results of the study should not be generalized to the entire populations of people with disabilities, because, as the research suggests, the population of these people is not homogeneous. Both within acquired disabilities and congenital ones there are people with various medical conditions which should be approached individually. This requires an interdisciplinary approach and multi-element evaluation of the ability of a person to function behind the wheel. This applies to both psychological (including mental fitness), health and technical aspects.

Realizing that the differences indicated in many aspects of psychomotor functioning between people with congenital and acquired disability may result from disorders in the functioning of the Central Nervous System (including the frontal lobe responsible for movement and executive functions, and cerebellum responsible for visual-motor coordination) which are more often associated with congenital disability (e.g. cerebral palsy, spinal bifida, spinal muscular atrophy, Polio), than with a disability acquired (e.g. lack of a limb or limb paresis, dwarfism, spinal cord injury) this comparison of these two groups of people was aimed at checking their capabilities mainly in the context of dealing with participation in road traffic. The current policy of many countries strives not to restrict the right to access to the goods of civilization, so that all people regardless of their physical fitness can feel safe in road traffic.

\section{Summary}

The disturbed functioning of the organism, whether due to disability from birth, acquired or associated with the aging process, can lead not only to social disability, but also to a significant mental strain on the individual. It is connected with the loss of partial or full capacity to organize your own activities, which in turn makes it difficult to meet needs and fulfil tasks imposed by the social environment. The presented research sets the direction for further explorations, mainly due to the small group of respondents, but they can nevertheless form the basis for further hypotheses and their verification.

Due to the results of the research, the factor that increases road safety may be a vehicle suitably adapted to the type of disability. Currently, the Polish market has many technical solutions that allow driving the vehicle in a safe and comfortable manner. Depending on the type of disability, there are various devices that adjust the car to be driven by a disabled person. These are most often: devices for manual accelerator, brake and/or clutch; knob mounted on the steering wheel of the vehicle, enabling one-handed operation; extension of pedals in the form of "overlays" or pedaliers; raised floor; lock of the accelerator pedals; power steering and brake system; raising the pedals: accelerator, brake and clutch; devices for operating rotating seats; mirrors supporting the field of observation to the rear, 
panoramic internal mirrors; four-point harness, used to avoid involuntary movement of the body on the seat during sudden braking; devices supporting wheelchair users: ramps, elevators to get in the car alone, automated, pilot-controlled booms "collecting" the wheel chair.

As a rule, disability does not prejudge whether a particular person may or may not be a driver, as long as it does not limit the ability to think and make decisions (although it may and sometimes makes their performance difficult). Each time it is an individual decision. Searching for solutions aimed at supporting the environment of people with dysfunctions, creating them development opportunities to counteract their marginalization should constitute an important element of activities in the area of improving road safety.

\section{References}

1. WHO, World report on disability (2011)

2. Statistics Poland, The health status of the Polish population in 2014, (2016)

3. P. Wolski, Niepełnosprawność ruchowa. Między diagnozą a działaniem (Centrum Rozwoju Zasobów Ludzkich, Warsaw, 2013)

4. J. Kirenko, Wsparcie społeczne osób z niepełnosprawnością (Wyższa Szkoła Umiejętności Pedagogicznych i Zarządzania, Ryki, 2002)

5. W. Cendrowski, Stwardnienie rozsiane. Wydanie II uzupełnione (PZWL, Warsaw, 1993)

6. T. Majewski, Rehabilitacja zawodowa osób niepełnosprawnych (Centrum BadawczoRozwojowe Rehabilitacji Osób Niepełnosprawnych, Warsaw, 1995)

7. S. Kowalik, Psychologia rehabilitacji (Wydawnictwa Profesjonalne i Akademickie, Warsaw, 2007) 